\title{
CRENAS
}

CENTRO RICERCHE

ECONOMICHE NORD SUD

Università di Cagliari

Università di Sassari

\section{AGGLOMERATION AND GROWTH IN THE NEG: A}

CRITICAL ASSESSMENT

Fabio Cerina

Francesco Pigliaru 


\title{
Agglomeration and Growth in the NEG: a critical assessment*
}

\author{
Fabio Cerina and Francesco Pigliaru \\ CRENoS and University of Cagliari \\ (Published as Chapter 5 of New Directions in Economic \\ Geography, (ed. by Bernard Fingleton), 2007, Edward Elgar)
}

\begin{abstract}
This chapter is divided into two parts. In the first part we review the main results of a typical "New Economic Geography and Growth" (NEGG) model (Baldwin and Martin, 2003) and assess the contribution of this literature to the issue of long-run income gaps between countries. In the second part we discuss the robustness in some results of these models which are directly linked to important policy implications and we show that these results crucially depend on very restrictive values of some parameters of the model. In particular, depending on the different values of the degree of love for variety and the elasticity of substitution between traditional and manufacturing goods, our analytical examples reveal that: a) when trade is costly enough the symmetric equilibrium might not be stable also when capital is perfectly mobile; b) the rate of growth might depend on the geographical allocation of industries also when spillovers are global and, c) when industrial firms are concentrated in only one region, countries might not grow at the same rate in real terms.
\end{abstract}

\section{Introduction}

Per-capita income gaps across states and even regions of a rich integrated area such as the EU are sizeable and persistent. As for inequality across regions, one of the most influential explanation stems from the idea that regions are highly specialized, and that productivity may differ across sectors. In Kaldor's influential explanation, trade can drive apart two almost identical regions by causing

*This chapter has been prepared for the book New Direction in Economic Geography, edited by Bernard Fingleton and to be published by Edward Elgar. We would like to thank Bernard Fingleton, Gianmarco Ottaviano, Frederic Andrès and Frederic Robert-Nicoud for useful insights and suggestions. We are also grateful to seminar participants at the University of Cambridge, Sassari and Cagliari for helpful comments. All remaining errors are our own. Corrensponding author: Fabio Cerina, CRENoS, Viale Fra Ignazio, 78 - 09123 - Cagliari (Italy) - e-mail: fcerina@unica.it 
industry to agglomerate in one location. This mechanism has been modelled in several papers on endogenous growth and trade (e.g., Lucas, 1988 and Grossman and Helpman, 1991). However, papers in this tradition do not take geography (i.e. transport costs) into account. More recently, the development of New Economic Geography literature has extended the Grossman and Helpman approach to include explicit mechanisms of agglomeration. In this chapter we will assess the contribution of recent models of agglomeration and economic growth to Kaldor's proposition. In the first part of the chapter we will explain, compare and discuss the new approach. In particular, we will then:

- review how the mechanism leading to (catastrophic) agglomeration of the high-tech sector works and assess the existence of core results across different models;

- explain and discuss what the economic consequences of catastrophic agglomeration are for the core and for the periphery.

In the second part, we will assess the analytical robustness of some important results which may be appealing for policymakers ${ }^{1}$. We will focus on the results according to which: 1) the symmetric equilibrium is always stable when capital is perfectly mobile; 2) the geographical allocation of industries does not affect the growth rate of innovation when spillovers are global; 3) agglomeration can be growth-enhancing both for the core (where agglomeration takes place) and for the periphery. These result have strong implications for regional policy and therefore deserves closer scrutiny. We aim to show that:

- in its current analytical formulation these result are far from robust;

- adopting a more general representation of consumers' preferences results in a less optimistic outlook on the consequences of agglomeration for the core and, above all, for the periphery;

The chapter is organized as follows: section 2 analyses the contribution of some recent developments in New Economic Geography to the issue of long-run income gaps among countries and the policy implications that can be drawn from the most important results of the studies in so-called "New economic geography and growth" (NEGG) literature. Section 3 discusses the robustness of some these results and shows how their validity is restricted to a very narrow set of parameters values. Section 4 concludes.

\section{NEG, growth and regional gap}

Kaldor famously wrote as far as back as 1970:

\footnotetext{
${ }^{1}$ The interest UE poses on the NEG literature is well-known. Great part of the working papers published by the European Investment Bank (the EU financing institution whose declared task is to contribute towards the integration, balanced development and economic and social cohesion of the Member Countries) are written by the leading exponents on the NEG literature strand.
} 
"When trade is opened up between them, the region with the more developed industry will be able to supply the need of the agricultural area of the other region on more favourable terms: with the result that the industrial centre of the second region will lose its market and will tend to be eliminated". (Kaldor, 1970, p.338)

But what conditions are really needed for this "catastrophic agglomeration" to occur? What are the consequences for the economy as a whole and for the periphery? Is there a case for regional policy? What kind of regional policy?

In the following section, we focus on finding the answer that NEG provides to these questions. More precisely, our aim is to assess the contribution of NEG in understanding what the sources and the growth-effect of agglomeration will be and how much the periphery should worry about agglomeration.

In order to do this, we focus on a typical NEGG model. We believe it is useful to stress some basic assumptions and some already known intermediate results because they will represent a benchmark for the second part of the chapter in which we will evaluate to what extent the policy implications of the NEG models are sensitive to small changes in the assumptions.

Our main references are Baldwin et. al (2004) and Baldwin and Martin (2003) who have supplied the most important results in this field. The original results are contained in Baldwin, Forslid (1999a,1999b and 2000), Martin and Ottaviano (1999 and 2000), Martin (1998), Baldwin, Martin and Ottaviano (2001) and Bellone and Maupertuis (2003) ${ }^{2}$

NEGG models can be thought of as the results of the meeting between two different strands of literature: new growth theory (Romer 1990, Grossman and Helpman 1991) and new economic geography (Krugman 1991, Krugman and Venables 1995). Many of the most popular NEG models focus on labour and don't take into account the accumulation of physical or knowledge capital. These models are therefore not suited to explaining the growth process. In order to ensure that these models are capable of creating sustained growth, most NEGG models make use of an instrument which is typical of endogenous growth theory: they add a capital producing sector which makes capital stock endogenous. The introduction of this sector, which represents the key analytical difference from the standard CP-models, allows for an analysis 1) of how new economic activities emerge as a consequence of technological innovations; 2) of the way these economic activities decide to locate. In other words, by means of NEGG models, the creation and localisation process of new firms can be considered as a unique process.

\subsection{Model structure and intermediate results}

Most existing geography and growth models adopt international settings where the migration of workers across regions or countries is not allowed for. This is

\footnotetext{
${ }^{2}$ Fujita and Thisse (2002) and Yamamoto (2002) belong to the class of GG models as well, but they adopt a framework which is slightly different from the one we would like to focus on in this work.
} 
because, in the majority of cases, the introduction of workers' migration into an endogenous growth model under perfect foresight raises difficult problems ${ }^{3}$. Accordingly, we will focus on a framework in which labour is immobile across regions but a core-periphery outcome is still possible if particular assumptions are made about capital mobility.

Apart from the introduction of the capital producing sector, the structure of NEGG models is almost identical to the most popular NEG models. The world is made of 2 regions, North and South, both endowed with 2 factors: labour $L$ and capital K. 3 sectors are active in both regions: manufacturing $M$, traditional good $T$ and a capital producing sector $I$. Regions are symmetric in terms of: preferences, technology, transport costs and labour endowment. As already stated, labour is assumed to be immobile across regions but mobile across sectors within the same region.

As in the CP models, the usual Dixit-Stiglitz $M$-sector (manufactures) consists of differentiated goods but, in this context, fixed cost is expressed in terms of $K$. Each variety requires one unit of capital which, according to the assumption on capital mobility, can be interpreted as an idea, a new technology, a patent, or machinery, etc.. Production also entails a variable cost ( $a_{M}$ units of labour per unit of output). Its cost function, therefore, is $\pi+w a_{M} x_{i}$, where $\pi$ is $K$ 's rental rate, $w$ is the wage rate, and $x_{i}$ is total output of a typical firm.

Each region's $K$ is produced by its $I$-sector which produces one unit of $K$ with $a_{I}$ unit of labour. So the production and marginal cost function for the $I$-sector are, respectively

$$
\begin{aligned}
\dot{K} & =Q_{K}=\frac{L_{I}}{a_{I}} \\
F & =w a_{I}
\end{aligned}
$$

Note that this unit of capital in equilibrium is also the fixed cost $F$ of the manufacturing sector. As one unit of capital is required to start a new variety, the number of varieties and of firms at the world level is simply equal to the capital stock at the world level: $K+K^{*}=K^{w}$. We denote $n$ and $n^{*}$ as the number of firms located in the north and south respectively. As one unit of capital is required per firm we also know that: $n+n^{*}=K^{w}$. However, depending on the assumptions we make on capital mobility, the stock of capital produced and owned by one region may or may not be equal to the number of firms producing in that region. In the case of capital mobility, the capital may be produced in one region but the firm that uses this capital unit may be operating in another region. Hence, when capital is mobile, the number of firms located in one region is generally different from the stock of capital owned by this region.

To individual $I$-firms, the innovation cost $a_{I}$ is a parameter. However, following Romer (1990), endogenous and sustained growth is provided by assuming that the marginal cost of producing new capital declines (i.e., $a_{I}$ falls) as the

\footnotetext{
${ }^{3}$ See for example Fujita and Thisse (2002) and Baldwin and Forslid (2000) who adopt a framework allowing for workers' mobility.
} 
sector's cumulative output rises. In the most general form, learning spillovers are assumed to be localised. The cost of innovation can be expressed as

$$
a_{I}=\frac{1}{A K^{w}}
$$

where $A \equiv s_{n}+\lambda\left(1-s_{n}\right)$ and $0<\lambda<1$ measures the degree of globalization of learning spillovers. The south's cost function is isomorphic, that is, $F^{*}=$ $w^{*} / K^{w} A^{*}$ where $A^{*}=\lambda s_{n}+1-s_{n}$. Notice that, when learning spillovers are global $(\lambda=1), A=A^{*}=1$. In the model version we examine, capital depreciation is ignored ${ }^{4}$. Because the number of firms, varieties and capital units is equal, the growth rate of the number of varieties, on which we focus, is therefore

$$
g \equiv \frac{\dot{K}}{K} ; g^{*} \equiv \frac{\dot{K}^{*}}{K^{*}}
$$

Finally, traditional goods, which are assumed to be homogenous, are produced by the $T$-sector under conditions of perfect competition and constant returns. By choice of units, one unit of $T$ is made with one unit of $L$. Basically, the traditional sector has no "active" role in these models but its existence in both regions has a crucial role on some of the implications of this class of models.

\subsubsection{Consumer choice}

The representative consumer is infinitely-lived and has the following preferences

$$
U_{t}=\int_{t=0}^{\infty} e^{-\rho t} \ln Q_{t} d t ; Q_{t}=C_{M}^{\mu} C_{T}^{1-\mu} ; C_{M}=\left[\int_{i=0}^{K+K^{*}} c_{i}^{1-1 / \sigma} d i\right]^{\frac{1}{1-1 / \sigma}}
$$

where $\rho$ is the rate of time preference, $\sigma$ is the constant elasticity of substitution among varieties, and the other parameters have their customary meaning. As usual, utility optimization can be thought of as a three-stage decision in which consumers first inter-temporally allocate their income between consumption and savings (according to a logarithmic utility function), then allocate consumption between manufacturing and traditional goods (according to a Cobb-Douglas utility function) and finally distribute manufacturing consumption across varieties (according to a CES utility function).

Intertemporal optimization implies that the time path of consumption expenditures $E$ is driven by the standard Euler equation

$$
\frac{\dot{E}}{E}=r-\rho
$$

with the interest rate $r$ satisfying the no-arbitrage-opportunity condition between investment in the safe asset and capital accumulation

$$
r=\frac{\pi}{F}+\frac{\dot{F}}{F}
$$

${ }^{4}$ See Baldwin (2000) and Baldwin et al. (2004) for similar analysis with depreciation 
where $\pi$ is the rental rate of capital and $F$ its asset value which, due to perfect competition in the $I$-sector, is equal to its marginal cost of production.

In the second stage, maximization of the second stage Cobb-Douglas utility function implies that a constant fraction of total northern consumption expenditure $E$ falls on $M$-varieties with the rest spent on $T$.

$$
\begin{aligned}
P_{M} C_{M} & =\mu E \\
p_{T} C_{T} & =(1-\mu) E
\end{aligned}
$$

where $p_{T}$ is the price of the traditional good and $P_{M}=\left[\int_{i=0}^{K+K^{*}} p_{i}^{1-\sigma} d i\right]^{\frac{1}{1-\sigma}}$ is the Dixit-Stiglitz perfect price index for the manufactured goods.

Finally, in the third stage, the amount of $M$ expenditures $\mu E$ is allocated across varieties according to the a CES demand function for a typical $M$ variety $c_{j}=\frac{p_{j}^{-\sigma}}{P_{M}^{1-\sigma}} \mu E$, where $p_{j}$ is variety $j$ 's consumer price. Southern optimization conditions are isomorphic.

\subsubsection{Firm's choice}

Due to perfect competition in the $T$-sector, the price of the agricultural good must be equal to the wage of the traditional sector's workers: $p_{T}=w_{T}$. Moreover, as long as both regions produce some $T$, the assumption of free trade in $T$ implies that not only price, but also wages are equalized across regions. It is therefore convenient to choose home labour as numeraire so that

$$
p_{T}=p_{T}^{*}=w_{T}=w_{T}^{*}=1
$$

Is it always the case that both regions produce some $T$ ? An assumption is actually needed in order to avoid complete specialization: a single country's labour endowment must be insufficient to meet global demand. Formally

$$
L^{*}=L<(1-\mu) \frac{\left(E+E^{*}\right)}{p_{T}}=(1-\mu)\left(E+E^{*}\right)
$$

The purpose of making this assumption is to maintain the $M$-sector wages fixed at the unit value. Since labour is mobile across sector, as long as the $T$ - sector is present in both regions, a simple arbitrage condition would suggest that wages of the two sectors cannot differ. Hence, $M-$ sector wages are tied to $T$-sector wages which, in turn, remain fixed at the level of the unit price of a traditional good. Therefore

$$
w_{M}=w_{M}^{*}=w_{T}=w_{T}=1
$$

As we might easily conclude, (7) holds even when the $M$ - sector disappears in one region. But it does not hold any longer in cases where there is full specialization. These cases are actually excluded a-priori by (6). However, as we shall see later, Bellone and Maupertuis (2003) show that by removing this 
assumption, and therefore allowing for complete specialization to occur and for wages to diverge, has no particular consequences on the divergence-convergence scenario.

Since wages are uniform e and all varieties' demand have the same constant elasticity $\sigma$, firms' profit maximisation yields local and export prices that are identical for all varieties no matter where they are produced: $p=w a_{M} \frac{\sigma}{\sigma-1}$. Then, imposing the normalization $a_{M}=\frac{\sigma-1}{\sigma}$ and (7), we finally have

$$
p=w=1
$$

As usual, since trade in $M$ is impeded by iceberg import barriers, prices for markets abroad are higher

$$
p^{*}=\tau p ; \tau \geq 1
$$

With monopolistic competition, equilibrium operating profit is given by the value of sales divided by $\sigma$. Due to free entry, this profit is entirely absorbed by the fixed cost of production (the rental rate of capital $\pi$ ). Thus, market clearing condition for each variety results in

$$
\begin{aligned}
\pi & =B \frac{\mu E^{w}}{\sigma K^{w}} ; B=\left[\frac{s_{E}}{s_{n}+\phi\left(1-s_{n}\right)}+\frac{\phi\left(1-s_{E}\right)}{\phi s_{n}+\left(1-s_{n}\right)}\right] \\
\pi^{*} & =B^{*} \frac{\mu E^{w}}{\sigma K^{w}} ; B^{*}=\left[\frac{\phi s_{E}}{s_{n}+\phi\left(1-s_{n}\right)}+\frac{\left(1-s_{E}\right)}{\phi s_{n}+\left(1-s_{n}\right)}\right]
\end{aligned}
$$

where $E^{w}=E+E^{*}$ is world total expenditure, $s_{E}=E / E^{w}$ is the north share of $E^{w}$ and $\phi=\tau^{1-\sigma}$ measures the freeness of trade since trade gets freer as $\phi$ rises from 0 (prohibitive costs) to 1 (costless trade).

Finally, considering the market clearing condition on $M$ and $T$ goods and labour market, we conclude that a steady state with constant a growth rate in the number of varieties (and hence a constant number of R\&D workers), will only exist if $E^{w}$ is itself constant.

$$
E^{w}=\left(2 L-L_{I}-L_{I}^{*}\right) \frac{\sigma}{\sigma-\mu} .
$$

\subsection{Does economic growth generate agglomeration?}

For the sake of simplicity, we shall answer this question by focusing on the case when spillovers are global $(\lambda=1)$. Allowing for localised learning spillovers will not change the nature of the answer to this question: if capital is immobile, an increase in the rate of capital growth in one of the two regions leads to a Core-Periphery outcome in the high-growth region.

By using a Tobin $q$ approach (Baldwin and Forslid 1999 and 2000), we know that the equilibrium level of investment (production in the $I$ sector) is characterized by the equality of the stock market value of a unit of capital (denoted with the symbol $V$ ) and the replacement cost of capital, $F$. With $E$ and $E^{*}$ constant in steady state, the Euler equation gives us $r=r^{*}=\rho$. Moreover, in steady state, the growth rate of the capital stock (or of the number 
of varieties) will be constant and will either be common $\left(g=g^{*}\right.$ in the interior symmetric case) or north's $g$ (in the core-periphery case) ${ }^{5}$. In either case, the steady-state values of investing in new units of $K$ are

$$
V_{t}=\frac{\pi_{t}}{\rho+g} ; V_{t}^{*}=\frac{\pi_{t}^{*}}{\rho+g}
$$

so that, using (9), (10), (2) and the labour market clearing condition,

$$
\begin{aligned}
q & =B\left(s_{E}, s_{n}\right) \frac{\mu E^{w}}{(\rho+g) \sigma} \\
q^{*} & =B^{*}\left(s_{E}, s_{n}\right) \frac{\mu E^{w}}{(\rho+g) \sigma}
\end{aligned}
$$

in equilibrium $q=q^{*}=1$ therefore, using (11) and the fact that, both in the symmetric and the CP equilibrium we have $B\left(s_{E}, s_{n}\right)=B^{*}\left(s_{E}, s_{n}\right)=1$, we can solve for the equilibrium rate of growth $g$

$$
g=\frac{2 \mu L-(\sigma-\mu) \rho}{\sigma}
$$

which tells us that the geographical allocation of the I - sector does not influence the rate of growth $\mathrm{g}$. As we will see later, this is true only if the cost of innovation is the same across regions, i.e when learning spillovers are global. Given that $L_{I}>0\left(L_{I}^{*}>0\right)$, investment will be positive if and only if $q \geq 1$ $\left(q^{*} \geq 1\right)$. Hence, starting from a symmetric equilibrium when $s_{n}=s_{E}=1 / 2$ and $q=q^{*}=1$, we can study the linkage between growth and agglomeration of economic activities by studying the behaviour of $q$ and $q^{*}$ as $s_{n}$ varies.

We thus have

$$
\begin{aligned}
\left.\frac{\partial B\left(s_{E}, s_{n}\right)}{\partial s_{E}}\right|_{s_{n}=1 / 2} & =-\left.\frac{\partial B^{*}\left(s_{E}, s_{n}\right)}{\partial s_{E}}\right|_{s_{n}=1 / 2}=2\left[\frac{1-\phi}{1+\phi}\right]>0 \\
\left.\frac{\partial B\left(s_{E}, s_{n}\right)}{\partial s_{n}}\right|_{s_{E}, s_{n}=1 / 2} & =-\left.\frac{\partial B^{*}\left(s_{E}, s_{n}\right)}{\partial s_{n}}\right|_{s_{E}, s_{n}=1 / 2}=-2\left[\frac{1-\phi^{2}}{1+\phi^{2}}\right]<\emptyset
\end{aligned}
$$

(14) tells us that a production shifting in the north (i.e. an increase in the number of firms located in the north) has, by itself, a negative effect: competition increases, sales and profit go down, the value of the firm becomes smaller than the replacement cost of capital and there is no more incentive to invest in the $I$ - sector. The opposite happens in the south.

\footnotetext{
${ }^{5}$ The dynamics of the share of manufacturing firms allocated in the north is

$$
\dot{s}_{n}=s_{n}\left(1-s_{n}\right)\left(\frac{\dot{K}}{K}-\frac{\dot{K}^{*}}{K^{*}}\right)
$$

so that only two kinds of steady state are possible: 1) one in which the rate of growth of capital is equalized across countries; 2) one in which the manufacturing industries are allocated and grow in only one region.
} 
If this were the only mechanism at work, the system would go back to symmetry. But (13) suggests that the story does not finish here. In fact, things are different if an increase in $s_{n}$ makes $s_{E}$ increase too. In this case, production shifting $\left(\partial s_{n}>0\right)$ leads to demand shifting $\left(\partial s_{E}>0\right)$ and profits in the north may grow enough to offset the negative effect of competition. If so, the typical north $I$ - sector firm now has the incentive to invest more, so $s_{n}$ increases further. The symmetric equilibrium will then become unstable and catastrophic agglomeration of $I$ and $M$ starts to take place.

So, in order to have catastrophic agglomeration, we need to answer "yes" to the following crucial questions: 1) does production shifting lead to demand shifting? 2) does production shifting lead to enough demand shifting? Identifying cases when the answer to both questions is "yes" means recognising the conditions under which catastrophic agglomeration takes place.

\subsubsection{Does production shifting leads to demand shifting?}

Given the structure of the model, the only case when the answer to this question is "yes" is if we assume capital to be immobile. Analogously to other NEG models, catastrophic agglomeration is due to a circular causality characterized by both production and demand shifting which reinforce each other. Production shifting takes the form of capital accumulation in one region (and de-accumulation in the other) and the demand shifting takes the form of an increase in permanent income in one region (and a decrease in the other) due to larger investment. With perfect capital mobility, firm's owners can decide where to locate production and profits are repatriated. Hence a production shifting does not lead to demand shifting.

By using (14), we can easily infer that, when capital is perfectly mobile, the symmetric equilibrium will be stable ${ }^{6}$. In fact, since with perfect mobility $s_{K}$ does not change with $s_{n}$, (a production shifting does not affect the distribution of capital) a small increase in $s_{n}$ will unambiguously lead to a decrease in the north's profits and an increase in the south's profits, so that firms are induced to go back in the south. The only active mechanism here is that, when more firms locate in the north, this increases competition there (and decreases it in the south).

By contrast, if capital is immobile, then firms cannot choose where to locate and firm owners are forced to invest in the region where they live $\left(s_{n}=s_{K}\right)$. In this case, gains from capital ownership have to be spent in the region where production takes place. Hence a production shifting results in demand shifting, i.e., a large number of firms located in a region implies that there will be a larger share of expenditure in the same region.

This happens because of a simple equilibrium relation between $s_{E}$ and $s_{K}$. In equilibrium, when $q=q^{*}=1$, we have the following:

$$
s_{E}=\frac{E}{E^{w}}=\frac{L+\rho s_{K}}{2 L+\rho}=\frac{1}{2}+\frac{\rho}{2 L+\rho}\left(s_{K}-\frac{1}{2}\right)
$$

\footnotetext{
${ }^{6}$ Actually, this is true for each possible initial allocation of firms.
} 
that is, an increase in the north's share of capital increases its permanent income and leads therefore to an increase in its share of expenditure. Since with capital immobility an increase in the north's share of firms corresponds to an increase in its share of capital $\left(s_{n}=s_{K}\right)$, then, following a small increase in $s_{n}$, the north's incentives to accumulate are now affected by another mechanism, that of demand linkages, which works on the opposite direction with respect to the competition effect (13).

We then need capital immobility to obtain a demand linkage effect from $s_{n}$ to $s_{E}$. However, this necessary condition for cumulative causation to take place, is not sufficient.

\subsubsection{Does production shifting leads to enough demand shifting?}

Differentiating $B$, we obtain the following

$$
d B\left(s_{n}, s_{E}\right)=\frac{\partial B}{\partial s_{n}} d s_{n}+\frac{\partial B}{\partial s_{E}} d s_{E}
$$

When capital is immobile and since $s_{n}=s_{K}$ and by (15) $\frac{d s_{E}}{d s_{n}}=\frac{\rho}{2 L+\rho}>0$, we will see that

$$
d B\left(s_{n}, s_{E}\left(s_{n}\right)\right)=\frac{\partial B}{\partial s_{n}} d s_{n}+\frac{\partial B}{\partial s_{E}} \frac{d s_{E}}{d s_{n}} d s_{n}
$$

In symmetry we have

$$
\left.\frac{d B\left(s_{n}, s_{E}\left(s_{n}\right)\right)}{d s_{n}}\right|_{s_{n}=s_{E}=1 / 2}=-\left.\frac{d B^{*}\left(s_{n}, s_{E}\left(s_{n}\right)\right)}{d s_{n}}\right|_{s_{n}=s_{E}=1 / 2}=\underbrace{-2\left[\frac{1-\phi^{2}}{1+\phi^{2}}\right]}_{\text {market-crowding effect }}+\underbrace{\left[\frac{1-\phi}{1+\phi}\right] \frac{\rho}{2 L+\rho}}_{\text {demand-linked effect }}
$$

Following a small increase in $s_{n}$, the north's profits increase, and so agglomeration takes place, whenever the market-crowding effect is offset by the demand-linked effect (which is absent in the case of perfect mobility). A quick examination reveals that this is the case when

$$
\phi>\frac{L}{L+\rho}=\phi_{C P}
$$

Hence, catastrophic agglomeration occurs if $d s_{n}>0$ when transport costs are sufficiently low. It can be shown that, if the same condition holds, the CP equilibrium becomes stable.

As usual, both effects decrease as trade becomes freer. But the marketcrowding effect decreases (in absolute value) faster than the demand-linked effect, so that, when transport costs which are low enough, the latter offsets the former and symmetric equilibrium becomes unstable and CP outcome will be reached with probability 1 .

To sum up, we can so far draw the following conclusions:

- capital immobility is a necessary and sufficient condition for economic integration (raising of $\phi$ ) to generate catastrophic agglomeration. No localised spillovers of knowledge are required for this result: although the 
cost of innovation is the same everywhere, a higher expenditure share in the core makes expected profits too low in the periphery.

- When spillovers are global, the the overall growth rate of the economy does not depend on the geographical allocation of economic activities

- While there is no inequality in the symmetric equilibrium, permanent income levels in the Core are higher than permanent income levels in the periphery where, by definition, capital just disappears (asimptotically). However, this difference remains constant in steady state. Indeed,

- by terms of trade, the growth rate of real income is the same across regions. We will come back to this issue later.

\subsection{Is agglomeration growth-enhancing?}

We are now interested in the growth-effect of agglomeration. As we have already mentioned, for agglomeration of $I$ and $M$ sectors to be growth enhancing, we need to modify some assumption of the model presented above. Although introducing localized spillovers is not the only way that geography can affect growth $^{7}$, this seems, to some extent, the most natural way ${ }^{8}$.

Within these class of models, localized spillovers (LS) means that the cost of $\mathrm{R} \& \mathrm{D}$ in one region depends only partially $(\lambda<1)$ on the other region's capital stock. Hence, innovation costs will also depend both on the stock and the allocation of overall capital stock. Therefore, taking into account that the wage rate is equal to $1,(2)$ becomes

$$
F=\frac{1}{A K^{w}}
$$

where $A \equiv s_{n}+\lambda\left(1-s_{n}\right)$. The south's expression for innovation costs is isomorphic.

From the viewpoint of geographical allocation equililbrium analysis, the main differences to note are that: 1$)$ the symmetric equilibrium becomes unstable for even higher trade costs $\left.\left(\phi_{\text {cat }}>\phi_{C P}\right) ; 2\right)$ the level of trade costs that causes symmetric equilibrium to become unstable $\left(\phi_{\text {cat }}\right)$ no longer coincides with the level of trade costs where the CP-equilibria becomes stable $\left(\phi_{C P^{\prime}}\right)$. In particular $\phi_{c a t}<\phi_{C P^{\prime}}<\phi_{C P}$ and for $\phi_{c a t}<\phi<\phi_{C P}$ two more interior stable equilibria emerge; 3) both $\phi_{c a t}$ and $\phi_{C P}$ are increasing in $\lambda$ so that if we are in a CP equilibria and $\lambda$ grows enough, the $\mathrm{CP}$ equilibrium becomes unstable and the system might go back to symmetry. A further difference regarding the nature

\footnotetext{
${ }^{7}$ Martin and Ottaviano (2001) generate a feedback between growth and agglomeration by assuming vertical linkages rather than local spillovers in innovation. Because the innovation sector uses manufacturing goods as an input, the location of manufacturing affects the cost of innovation through trade costs. Yamamoto (2002) presents a similar model with circular causation between growth and agglomeration coming from the vertical linkages between the intermediate goods sector and the innovation sector.

${ }^{8}$ For an empirical and theoretical support of this assumption see, respectively Moreno, Paci and Usai (2003) and Duranton and Puga (2002).
} 
of agglomeration is that while we still observe that a $\mathrm{CP}$ outcome (catastrophic agglomeration of the $M$ sector in only one region) will emerge if and only if capital is immobile, a full concentration of the $I$ sector may also occur when capital is perfectly mobile. Due to localized spillovers, in fact, it is less costly to innovate in the region with the highest number of firms. This implies that, because of perfect capital mobility, all the innovation will take place in the region with a higher number of firms. In any case, the other region will be able to simply buy (without trade costs) innovations or capital produced in the innovating region.

But, as far as policy rules are concerned, the most significant differences concern to the issue of growth: in an LS-world the geographical allocation of manufacturing firms affects the global growth rate. Using the optimal investment condition $q=q^{*}=1$, we find that, in the symmetric equilibrium (for $s_{n}=1 / 2$ )

$$
g_{S}=\frac{(1+\lambda) \mu L-(\sigma-\mu) \rho}{\sigma}
$$

while, in the CP outcome (when $s_{n}=1$ )

$$
g_{C P}=\frac{2 \mu L-(\sigma-\mu) \rho}{\sigma}
$$

The latter is identical to the solution when spillovers are global since, in the CP outcome, all innovators are located in the same region so that learning is not affected by the degree of localization $\lambda$. Since $\lambda<1$, we have that $g_{C P}>g_{S}$ : when industry is spread across the two regions, spillovers are minimized, the cost of innovation is maximum and the global growth rate is minimum.

\subsection{The rate of growth of consumption and real income}

NEGG models like those presented above are not able to explain differences in the long-run rate of growth of consumption and real income between core and peripheral regions: real GDP and consumption growth rate in the two regions are identical in both the GS and the LS cases. And, most importantly, real GDP and consumption growth rate is the same in the two regions in the interior equilibrium (where both are innovating) as well as in the CP equilibria (where only one is doing so). This is due to the fact that real growth stems from the constant fall in the price index that is driven by a continuously widening range of varieties and which is common to the two regions. The price index for manufactures can be rewritten as

$$
\begin{aligned}
& P_{M}=\left(s_{n}+\left(1-s_{n}\right) \phi\right)^{\frac{1}{1-\sigma}} K^{w \frac{1}{1-\sigma}} \\
& P_{M}^{*}=\left(\phi s_{n}+\left(1-s_{n}\right)\right)^{\frac{1}{1-\sigma}} K^{w \frac{1}{1-\sigma}}
\end{aligned}
$$

where $P_{M}^{*}$ is the price index for the south.

Taking the rate of growth in the steady state, where $\dot{s}_{n}=0$, we find that

$$
\frac{\dot{P}_{M}}{P_{M}}=\frac{\dot{P}_{M}^{*}}{P_{M}^{*}}=\frac{1}{1-\sigma} \frac{\dot{K}^{w}}{K^{w}}=-\frac{g}{\sigma-1}
$$


Hence, prices for manufactures decreases at the same rate in both regions, regardless of the transport costs and the steady-state allocation of industries. But the global price level depends also on the price of the traditional good. Since the latter is our numeraire, the perfect price index associated to the second-stage Cobb-Douglas utility is then

$$
P=P_{M}^{\mu} ; P^{*}=P_{M}^{* \mu}
$$

which, finally, gives us the following growth rate of prices

$$
\frac{\dot{P}}{P}=\frac{\dot{P}^{*}}{P^{*}}=-\frac{\mu g}{\sigma-1}
$$

Once again, the growth rate of global prices is the same across regions regardless of both transport costs and the geographical allocation of firms.

Steady state nominal income in the two regions is the sum of labour income plus profit income and can be written as

$$
\begin{aligned}
Y & =L+\pi s_{K} K^{w}=L+B\left(\bar{s}_{n}, \bar{s}_{E}\right) \frac{\mu E^{w}}{\sigma} \\
Y^{*} & =L+\pi^{*}\left(1-s_{n}\right) K^{w}=L+B\left(\bar{s}_{n}, \bar{s}_{E}\right) \frac{\mu E^{w}}{\sigma}
\end{aligned}
$$

Being $s_{n}, s_{E}$ and $E^{w}$ constant in steady state, $Y$ and $Y^{*}$ are constant as well. The common long-run growth rate of real income is therefore

$$
\frac{\dot{Y}}{Y}-\frac{\dot{P}}{P}=\frac{\dot{Y}^{*}}{Y^{*}}-\frac{\dot{P}^{*}}{P^{*}}=\frac{\mu g}{\sigma-1}
$$

We should stress that, since the long-run growth rate of real income is the same across countries regardless of the geographical allocation of industries, countries grow at the same real long-run rate even in $\mathrm{CP}$ equilibrium, where $s_{n}=1$. In this case, although long-run nominal incomes differ,

$$
\begin{aligned}
Y & =L+\frac{\mu E^{w}}{\sigma} \\
Y^{*} & =L
\end{aligned}
$$

the long-run growth rate of prices and real income are still represented by (19) and (20). In other words, while the level of real incomes can differ across regions, the growth rate can only differ in the medium term, that is, as the economy approaches its long-run equilibrium. In the long run, regional real income growth rates are identical.

As for consumption, we have that in the $\mathrm{CP}$ equilibrium both regions displays the following consumption level

$$
\begin{aligned}
Q_{C P} & =\frac{E}{P}=\left(L+\frac{\mu E^{w}}{\sigma}-g\right) \frac{1}{P} \\
Q_{C P}^{*} & =\frac{E^{*}}{P^{*}}=\frac{L}{P^{*}}
\end{aligned}
$$


Where $Q_{C P}>Q_{C P}^{*}$ but $\frac{\dot{Q}_{C P}}{Q_{C P}}=\frac{\dot{Q}_{C P}^{*}}{Q_{C P}^{*}}=\frac{\mu g}{\sigma-1}$

Why should it be so? Consider the CP equilibrium: although the South is completely specialized in the traditional sector and does not innovate or indeed make any investment of any kind, it experiences the same rate of growth as the North due to continual terms-of-trade gains. In other words, thanks to the technological progress in the industrial sector, the price index of the manufacturing goods decreases faster than the price of the agricultural good. This means that the relative value of the commodity in which the periphery specializes - agricultural goods - increases overtime making the periphery's imports of manufacturing goods cheaper. As a result, the real income of the periphery grows, in the long-run, at the same rate of the core. As we will see later, this result crucially depends on the particular functional forms chosen to represent individual preferences.

\subsection{Main results and policy implications}

We now summarize the main results of the NEGG models, focusing on the periphery in the $\mathrm{CP}$ equilibrium. Results are summarized in the following table

\begin{tabular}{|l|l|l|l|l|}
\hline & GS K-mob. & GS K-imm & LS K-mob & LS K-imm \\
\hline Cat. Agglomeration in $I-M$ & NO & YES & YES - NO & YES \\
\hline Static losses for the periphery & NO & YES & NO & YES \\
\hline Dyn. gains for the periphery & NO & NO & YES & YES \\
\hline Dyn. losses for the periphery & NO & NO & NO & NO \\
\hline & & & & \\
\hline
\end{tabular}

What we first notice is that core results are not easy to identify: we have too many cases which are based on extreme assumptions. These difficulties are well represented by the sharp contrast between the LS case with capital immobility and the GS case with capital mobility. So how much should a periphery worry about agglomeration in the other region? Very little if the "true" model is the one with capital mobility: first, when spillovers are global, the allocation of manufacturing industries and knowledge sectors is always stable so that there is no chance of a CP outcome occuring unless we start from such an initial condition. Second, when spillovers are localized, people should be only too happy to see their region's R\&D sector disappear. With this sector being perfectly competitive, the periphery does not suffer any static or dynamic losses after the agglomeration process of the $I$ sector. By contrast, the concentration of the entire $I$ sector in the other region, allows for learning spillovers to be exploited at their maximum degree and, hence, the periphery $M$ - sector and real income grow at the maximum speed.

If the "true" model is instead the one with capital immobility, the outcomes are slightly less favourable for the periphery albeit not tragic. When spillovers are global, the periphery suffers from a static loss due to the fact that, since the $M$ - goods are produced only in the core, the periphery has to face a higher cost 
of living because trade costs are positive and this lowers its long-run permanent income level with respect to the symmetric equilibrium. On the other hand, when spillovers are localized, the periphery's worries for the static losses may or may not be offset by the dynamic gains achieved through the higher growth rate of knowledge. In both cases, the peripheral region will not suffer any dynamic losses following the agglomeration of the $M$ and the $I$ sector in the other region.

Hence, a policy-maker that takes NEGG models seriously, can draw two main messages from these models' results:

1. "if you are interested in long-run income of the periphery, do not worry too much about the agglomeration of the $M$ sector in the core". As we can see from the table, and as we have analysed before, the periphery never suffers from dynamic losses in the long-run since the rate of growth of its real income is always equal to the one of the core region. From the dynamic viewpoint, in a GS world, agglomeration of the $M$ sector in the core is at most indifferent for the periphery. While, in a LS world, it might also be beneficial for the periphery because it allows for the real rate of growth, which is equal to that of the core, to be maximum.

2. "In a LS-world, be careful with policies aimed at keeping R\&D activity in the periphery, since they could 1) harm the aggregate growth; 2) harm the periphery"

Both messages seem to imply that regional inequalities might be the price to pay in order to reach a higher aggregate growth and to maximize long-run welfare even in the periphery. If these implications turn out to be analytically robust (and empirically relevant), then the contribution of the NEG to the understanding of regional problems and policy would be highly valuable. But are they?

\section{Agglomeration and growth with CES second- stage utility: a discussion}

In the following sections we will show that the rather optimistic results of the NEGG models for the periphery become more pessimistic if the assumptions we are using are slightly changed. We then discuss the consequences of a slight variation in two parameters of this class of models: the elasticity of substitution between manufacturing and traditional goods in the second-stage utility function and the so-called degree of love for variety. Most (if not all) NEGG models: 1) make use of Cobb-Douglas (CD) second-stage instant utility function as in (3) which displays unitary elasticity of substitution between goods of the two kinds and 2) reduce the dimensionality of the parameter space by linking the marginal taste for an additional variety (what we call the "love for variety" parameter) to another crucial parameter: the elasticity of substitution across varieties ${ }^{9}$.

\footnotetext{
${ }^{9}$ This point is well clarified by Benassy (1996). In general, assume that the instantaneous utility function is $U\left[C_{T}, C_{M}\right]$ with $C_{M}=V_{n}\left(c_{1}, . ., c_{n}\right)$ homogeneous of degree one. We can
} 
This choice allows for a number of results and important simplifications. First, with CD preferences the expenditure shares in the two kinds of goods remain fixed and hence they are not affected by changes in relative prices. A different (albeit constant) value of the elasticity of substitution between the two kinds of goods triggers some important mechanisms which, although not easily tractable, cannot emerge with unitary elasticity of substitution. Second, the real growth rate of income and consumption crucially depends on the value of the love for variety parameter which, in most NEG models ${ }^{10}$ is fixed at $v=\frac{1}{\sigma-1}$.

It should be stressed here that our intention is not to build a model but rather to discuss the analitycal source of some important (and optimistic) results of NEGG models and to provide some examples (not necessarily more restrictive and in most cases more general) in which such optimistic results for the periphery are not obtained. To this end, we first introduce the following preference structure for a representative consumer

$$
\begin{aligned}
U_{t} & =\int_{t=0}^{\infty} e^{-\rho t} \ln Q_{t} d t ; Q_{t}=\left[\delta\left(n^{w^{v+\frac{1}{1-\sigma}}} C_{M}\right)^{\alpha}+(1-\delta) C_{T}^{\alpha}\right]^{\frac{1}{\alpha}} ; C_{M}=\left[\int_{i=0}^{K+K^{*}} c_{i}^{1-1 / \sigma} d i\right]^{\frac{1}{1-1 / \sigma}}(23) \\
\alpha & \leq 1
\end{aligned}
$$

The preference structure identified by (23) generalizes (3) in two directions. First, it considers a CES second-stage instant utility function which. This functional form still displays a constant elasticity of substitution between $M$ and $T$ goods, yet in this case the elasticity of substitution is equal to $\frac{1}{1-\alpha}$ which can be greater or lower than unity (as in the CD case) according to whether $\alpha$ is respectively negative or positive. Under CES preferences specified here, the expenditure shares of the final goods are not fixed but depend on the price index of manufacturing goods.

Second, adopting the same approach as Dixit and Stiglitz (1975), Benassy (1996) and Smulders and Van de Klundert (2003), the love for variety parameter $v$ is explicitly considered. In the typical NEGG models it takes the value of $\frac{1}{\sigma-1}$ so that love of variety is intrinsically linked to the elasticity of substitution across varieties $\sigma$ but in a more general context, as in (23), love of variety need not to be tied to $\sigma$.

define a function $\gamma(n)$ that represent the taste for variety and that depicts the utility gain derived from spreading a certain amount of production between $n$ differentiated products instead of concentrating it on a single variety

$$
\gamma(n)=\frac{V_{n}\left(c_{1}, . ., c_{n}\right)}{V_{1}(n q)}=\frac{V_{n}(1, . ., 1)}{n}
$$

Our love for variety parameter is simply the elasticity of $\gamma$

$$
\begin{aligned}
& \qquad v(n)=\frac{n \gamma^{\prime}(n)}{\gamma(n)} \\
& \text { It's easy to verify that when } C_{M}=\left(\int c_{i}^{\frac{\sigma-1}{\sigma}} d i\right)^{\frac{\sigma}{\sigma-1}} \text { we have } \gamma(n)=\frac{1}{\sigma-1} . \\
& { }^{10} \text { Murata (2004) is an exception to this respect. }
\end{aligned}
$$


For $\alpha=0$ we have a uniti value of the elasticity of substitution between goods $M$ and $T$ and the resultin utility function $Q_{t}=\left(n^{w^{v+\frac{1}{1-\sigma}}} C_{M}\right)^{\delta} C_{T}^{1-\delta}$ is identical to the previous CD case except for the multiplicative term $n^{w^{v+\frac{1}{1-\sigma}}}$. For $v=\frac{1}{\sigma-1}$ and $\alpha=0$ the utility function collapses to the previous case.

In what follows, we show how some important results of the NEGG models crucially depend on particular values of these parameters and are not robust to slight changes. In particular we will show that, according to different values of $v$ and $\alpha$, a) when trade is costly enough the symmetric equilibrium might not be stable even when capital is perfectly mobile; b) the rate of growth might depend on the geographical allocation of industries even when spillovers are global; and, c) in the CP outcome, countries might not grow at the same rate in real terms.

\subsection{Intermediate results with CES utility}

Taking the $T$ - good as numeraire, second-stage utility maximization leads to the following demand functions

$$
\begin{aligned}
C_{M} & =\frac{E}{P_{M}} \mu\left(n^{w}, P_{M}\right) \\
C_{T} & =E\left(1-\mu\left(n^{w}, P_{M}\right)\right)
\end{aligned}
$$

where now the expenditure share for manufactures is given by

$$
\mu\left(n^{w}, P_{M}\right)=\frac{1}{1+\left(n^{w \frac{1}{\sigma-1}-v} P_{M}\right)^{\frac{\alpha}{1-\alpha}}\left(\frac{1-\delta}{\delta}\right)^{\frac{1}{1-\alpha}}}
$$

Notice that (24) and (25) differ from (4) and (5) in that the expenditure shares are not fixed. In particular, it's easy to see that when $\alpha$ is positive, the expenditure shares on $M$ - goods tends to increase as the price index of the $M$ goods goes down. Substituting the expression for $P_{M}$ with (16) and (17), we can write

$$
\begin{aligned}
\mu\left(n^{w}, s_{n}, \phi\right) & =\frac{1}{1+\left(n^{w}\right)^{-\frac{\alpha v}{1-\alpha}}\left(s_{n}+\left(1-s_{n}\right) \phi\right)^{\frac{\alpha}{(1-\alpha)(1-\sigma)}\left(\frac{1-\delta}{\delta}\right)^{\frac{1}{1-\alpha}}}} \\
\mu^{*}\left(n^{w}, s_{n}, \phi\right) & =\frac{1}{1+\left(n^{w}\right)^{-\frac{\alpha v}{1-\alpha}}\left(\phi s_{n}+\left(1-s_{n}\right)\right)^{\frac{\alpha}{(1-\alpha)(1-\sigma)}}\left(\frac{1-\delta}{\delta}\right)^{\frac{1}{1-\alpha}}}
\end{aligned}
$$

We can make a number of observations from analysing these two expressions.

First, when the elasticity of substitution between the two goods is different to 1 , (i.e. $\alpha \neq 0)$, north and south expenditure shares differ $\left(\mu \neq \mu^{*}\right)$ in correspondence to any geographical allocation of the manufacturing industry 
except for $s_{n}=1 / 2$ (symmetric equilibrium). In particular, we find that ${ }^{11}$

$$
\begin{aligned}
& \alpha>\quad(<) 0 \Rightarrow \frac{\partial \mu}{\partial s_{n}}=\frac{\alpha(1-\phi) \mu(1-\mu)}{(1-\alpha)(\sigma-1)\left(\left(s_{n}+\left(1-s_{n}\right) \phi\right)\right)}>(<) 0 \\
& \alpha>\quad(<) 0 \Rightarrow \frac{\partial \mu^{*}}{\partial s_{n}}=\frac{\alpha(\phi-1) \mu^{*}\left(1-\mu^{*}\right)}{(1-\alpha)(\sigma-1)\left(\left(s_{n}+\left(1-s_{n}\right) \phi\right)\right)}<(>) 0
\end{aligned}
$$

Hence, when $\alpha>0$, a production shift in the north $\left(\partial s_{n}>0\right)$ leads to a relative increase in the southern price index fot the $M$ goods because southern consumers have to buy a larger fraction of $M$ goods from the north, which are more expensive because of trade costs. Unlike the CD case, where this phenomenon had no consequences on the expenditure shares for manufactures which remained constant across time and space, in the CES case expenditure shares on $M$ goods are influenced by the geographical allocation of industries because they depend on relative prices and relative prices change with $s_{n}$.

Secondly, we have

$$
\begin{aligned}
& \alpha \quad>\quad(<) 0 \Rightarrow \frac{\partial \mu}{\partial \phi}=\frac{\alpha\left(1-s_{n}\right) \mu(1-\mu)}{(1-\alpha)(\sigma-1)\left(\left(s_{n}+\left(1-s_{n}\right) \phi\right)\right)}>(<) 0 \\
& \alpha>\quad(<) 0 \Rightarrow \frac{\partial \mu^{*}}{\partial \phi}=\frac{\alpha s_{n} \mu^{*}\left(1-\mu^{*}\right)}{(1-\alpha)(\sigma-1)\left(\left(s_{n}+\left(1-s_{n}\right) \phi\right)\right)}>(<) 0
\end{aligned}
$$

So that, when $\alpha>0$, economic integration gives rise to an increase in the expenditure share for manufactured goods in both regions. Obviously, the smaller the share of manufacturing firms already present in the north (south), the larger the increase in expenditure share for the $M$ good in the north (south).

Third, and more importantly, by calculations we obtain the following

$$
\begin{aligned}
& \alpha>(<) 0 \Rightarrow \frac{\partial \mu}{\partial n^{w}}=\frac{\alpha v}{1-\alpha} \frac{(1-\mu) \mu}{n^{w}} \geq(\leq 0) \\
& \alpha>(<) 0 \Rightarrow \frac{\partial \mu^{*}}{\partial n^{w}}=\frac{\alpha v}{1-\alpha} \frac{\left(1-\mu^{*}\right) \mu^{*}}{n^{w}} \geq(\leq 0)
\end{aligned}
$$

Therefore, when goods are good substitutes $(\alpha>0)$, and unless individuals do not love variety $(v=0)$, the expenditure share for the $M$ - goods is in both regions an increasing function of the total number of varieties. In the analytical context of the NEGG models, this result (which is a feature of the CES utility function we have chosen) has highly unwelcome effects from the viewpoint of formalizing the dynamics of the model. However, although the dynamic properties of this model are highly complex, they are not complex enough to obscure the fact that, when $v$ and $\alpha$ are strictly positive, the two countries might grow at a different real growth rate.

Moreover, it is worth noticing that when $v=0$, which is simply a "different" but "equally restrictive" case with respect to the typical NEGG model ${ }^{12}, \mu$ and

\footnotetext{
${ }^{11}$ For simplicity's sake we omit the arguments of the functions $\mu$ and $\mu^{*}$.

${ }^{12}$ Murata (2004) uses this utility function to show the relation between agglomeration and structural change. This assumption can also be found in the "new Keynesian economics" literature (see Blanchard and Kiyotaki (1987, p.649), for example), which is another strand of literature based on the model of monopolistic competition by Dixit and Stiglitz (1977)
} 
$\mu^{*}$ are both constant in steady state since they are not affected by the increase in the number of varieties any longer $\left(\frac{\partial \mu}{\partial n^{w}}=\frac{\partial \mu^{*}}{\partial n^{w}}=0\right.$ when $\left.v=0\right)$. Indeed, by eliminating the love for variety, the expenditure shares are only affected by the price index through the transport cost $\phi$, which is our exogenous parameter, and through the allocation of industrial activitiy $\left(s_{n}\right)$ which is constant along the balanced growth path.

In what follows, we will focus on three issues whose analysis leads to conclusions which are shown to be highly dependent on the value of the parameters $\alpha$ and $v$. In dealing with the first two issues (the stability properties of the symmetric equilibrium and the influence of geographical allocation in the growth rate of the technological progress) we will focus on the case where $v=0$ and $\alpha$ may assume any positive value ${ }^{13}$ between 0 and 1 . When looking at the growth differentials in the real income between the two countries (our third issue), a positive $v$ is needed in order to obtain a positive growth gap.

\subsection{The stability of the symmetric equilibrium when $v=0$}

The lack of love for variety allows us to focus on how a decline in transportation costs affects expenditure shares owing to a rise in the real purchasing power. When $v=0$ we find

$$
\begin{aligned}
\mu\left(s_{n}, \phi\right) & =\frac{1}{1+\left(s_{n}+\left(1-s_{n}\right) \phi\right)^{\frac{\alpha}{(1-\alpha)(1-\sigma)}}\left(\frac{1-\delta}{\delta}\right)^{\frac{1}{1-\alpha}}} \\
\mu^{*}\left(s_{n}, \phi\right) & =\frac{1}{1+\left(\phi s_{n}+\left(1-s_{n}\right)\right)^{\frac{\alpha}{(1-\alpha)(1-\sigma)}}\left(\frac{1-\delta}{\delta}\right)^{\frac{1}{1-\alpha}}}
\end{aligned}
$$

By eliminating the love for variety we are able to maintain a version of the typical assumption in NEGG models which states that a single country's labour endowment must be insufficient to meet global demand. We are entitled to do this because, when $v=0$, both $\mu$ and $\mu^{*}$ cannot reach the unit value. This assumption should be modified as follows:

$$
L<\left(\left[1-\mu\left(s_{n}, \phi\right)\right] s_{E}+\left[1-\mu^{*}\left(s_{n}, \phi\right)\right]\left(1-s_{E}\right)\right) E^{w}, \forall\left(s_{n}, \phi\right) \in(0,1) \subset \mathbb{R}^{2}
$$

Since

$$
E^{w}\left(s_{E}, s_{n}, \phi\right)=\frac{\left(2 L-L_{I}-L_{I}^{*}\right) \sigma}{s_{E}\left(\sigma-\mu\left(s_{n}, \phi\right)\right)+\left(1-s_{E}\right)\left(\sigma-\mu^{*}\left(s_{n}, \phi\right)\right)}
$$

is constant in steady state, and $s_{E}$ has to be constant by definition, (34) can be accepted without particular loss of generality.

\footnotetext{
${ }^{13}$ The analysis can also be developed for any $\alpha \in(-1,0)$ but, for simplicity's sake, we focus on the case where goods are good susbstitutes which, as suggested by Lucas (1988), appears to be the most interesting one.
} 
North and south profits respectively become

$$
\begin{aligned}
\pi & =\left[\frac{s_{E}}{s_{n}+\phi\left(1-s_{n}\right)} \mu\left(s_{n}, \phi\right)+\frac{\phi\left(1-s_{E}\right)}{\phi s_{n}+\left(1-s_{n}\right)} \mu^{*}\left(s_{n}, \phi\right)\right] \frac{E^{w}}{\sigma K^{w}} \\
\pi^{*} & =\left[\frac{\phi s_{E}}{s_{n}+\phi\left(1-s_{n}\right)} \mu\left(s_{n}, \phi\right)+\frac{\left(1-s_{E}\right)}{\phi s_{n}+\left(1-s_{n}\right)} \mu^{*}\left(s_{n}, \phi\right)\right] \frac{E^{w}}{\sigma K^{w}}
\end{aligned}
$$

In the symmetric equilibrium, north and south expenditure shares are given by

$$
\left.\mu\left(s_{n}, \phi\right)\right|_{s_{n}=1 / 2}=\left.\mu^{*}\left(s_{n}, \phi\right)\right|_{s_{n}=1 / 2}=\frac{1}{1+\left(\frac{1+\phi}{2}\right)^{\frac{\alpha}{(1-\alpha)(1-\sigma)}}\left(\frac{1-\delta}{\delta}\right)^{\frac{1}{1-\alpha}}}
$$

so that world expenditure is given by

$$
\left.E^{w}\left(s_{n}, \phi\right)\right|_{s_{n}=1 / 2}=\frac{\left(2 L-L_{I}-L_{I}^{*}\right) \sigma}{\sigma-\mu\left(\frac{1}{2}, \phi\right)}
$$

and profits can be written as

$$
\pi=\pi^{*}=\frac{(2 L-g)}{K^{w}} \frac{\mu\left(\frac{1}{2}, \phi\right)}{\sigma-\mu\left(\frac{1}{2}, \phi\right)}
$$

What is the effect of a production shifting in the north on profits? From (28) and (29) we find that

$$
\left.\frac{\partial \mu\left(s_{n}\right)}{\partial s_{n}}\right|_{s_{n}=s_{E}=1 / 2}=-\left.\frac{\partial \mu^{*}\left(s_{n}\right)}{\partial s_{n}}\right|_{s_{n}=s_{E}=1 / 2}=2 \frac{1-\phi}{1+\phi} \frac{\alpha\left(\frac{1+\phi}{2}\right)^{\frac{\alpha}{(1-\alpha)(1-\sigma)}}\left(\frac{1-\delta}{\delta}\right)^{\frac{1}{1-\alpha}}}{(1-\alpha)(\sigma-1)\left(1+\left(\frac{1+\phi}{2}\right)^{\frac{\alpha}{(1-\alpha)(1-\sigma)}}\left(\frac{1-\delta}{\delta}\right)^{\frac{1}{1-\alpha}}\right)}>0
$$

In words, production shifting leads to a relative increase in the southern price index of $M$ goods because southern consumers have to buy a larger fraction of $M$ goods from the north which are more expensive because of trade costs. In the $\mathrm{CD}$ case, this phenomenon has no consequences on expenditure shares for manufactures which are exogenously fixed and remain constant across time and space. But in the CES case expenditure shares on $M$ goods depend on relative prices and the latter change with the geographical allocation of industries. By a sort of home market effect, the decrease in southern demand is more than compensated for by the increase in northern consumers' demand. This change in relative demands will have some consequences on relative profits.

Let us start with the case of capital mobility where production shifiting does not lead to a change in the regional allocation of capital (i.e., generally, $\left.s_{n} \neq s_{K}\right)$. Therefore, the effect of production shifting in the north on the relative profits can be written as

$$
\left.\frac{\partial\left(\pi / \pi^{*}\right)}{\partial s_{n}}\right|_{s_{n}=s_{E}=1 / 2}=\underbrace{2 \frac{(1-\phi)^{2}}{(1+\phi)^{2}} \frac{\alpha}{(1-\alpha)(\sigma-1)}\left(\frac{1+\phi}{2}\right)^{\frac{\alpha}{1-\alpha)(1-\sigma)}}\left(\frac{1-\delta}{\delta}\right)^{\frac{1}{1-\alpha}}}_{\text {Price effect }}-\underbrace{2 \frac{(1-\phi)^{2}}{(1+\phi)^{2}}}_{\text {market-crowding effect }}
$$


If we compare this expression with (14), we can easily notice that, thanks to the change in $\mu$, the negative influence of the market crowding effect is now mitigated (and might be offset) by a positive effect on profits which was not present in the CD case. Unlike before, north profits might increase because of the larger domestic demand of manufacturing goods due to the increase in the domestic expenditure share $\mu$ following a reduction in the domestic price index. This new agglomeration force, which we call price effect, vanishes as trade becomes freer at a speed which is lower than market-crowding effect.

The price effect offsets the market-crowding effect, and hence relative profits in the north increase after production shifting when

$$
\left.\frac{\partial\left(\pi / \pi^{*}\right)}{\partial s_{n}}\right|_{s_{n}=s_{E}=1 / 2}>0: \phi<\phi_{S}(\alpha, \sigma, \delta)
$$

where $\phi_{S}(\alpha, \sigma, \delta)=2\left(\frac{\alpha}{(1-\alpha)(\sigma-1)}\right)^{\frac{(1-\alpha)(\sigma-1)}{\alpha}}\left(\frac{1-\delta}{\delta}\right)^{\frac{\sigma-1}{\alpha}}-1$.

This means that the symmetric equilibrium is stable not for any value of $\phi$, but only when $\phi$ is low enough. In other words, the presence of a new agglomeration force makes for a new possible scenario where symmetric equilibrium may be unstable even when capital is mobile. But unlike in the case with capital immobility and CD preferences, the symmetric equilibrium is unstable for low values of $\phi$, that is, when trade is costly enough. This might be considered as a case of stabilizing integration. When trade is costly, production shifting in the north will result in a relevant reduction (increase) in north (south) prices which leads to a relevant increase (reduction) in northern (southern) expenditure shares for the $M$ - goods. In other words, as $\mu$ is positively influenced by $s_{n}$, northern consumers spend a larger fraction of their income on manufacturing goods. Northern profits benefit from such an increase in the domestic demand and if trade is costly enough this positive demand effect may offset the negative congestion effect and therefore increase the north's profits. As a consequence, southern firms have a further incentive to relocate their activities in the north and, as long as trade remains costly enough, this process leads to the disappearence of the industrial sector in the south and to a perfect concentration of the $M-$ sector in the north. It is worth highlighting that, being the expenditure shares fixed, this possibility was discarded in the CD case. Obviously, since half of the firms have southern ownerx $\left(s_{n}\right.$ may go to unity, but $\left.s_{K}=1 / 2\right)$, the south can still enjoy profit gainx deriving from the industrial sector. However, in equilibrium, south consumers enjoy a lower level of utility since their real income is lower due to higher prices $\left(P^{*}>P\right)$.

But as trade becomes freer, the positive effect of production shifting on the price index diminishes to the extent that the price effect is not large enough to compensate for the negative effect of tougher competition. Hence, when trade is free enough $\left(\phi<\phi_{S}(\alpha, \sigma, \delta)\right)$, northern profits decrease following production shifting to the north, southern firms are motivated to move back to the north and symmetric equilibrium once again becomes stable. Close inspection of the expression for $\phi_{S}(\alpha, \sigma, \delta)$ reveals that, according to the different values of the 
parameters $\alpha, \sigma$ and $\delta$, three outcomes are possible:

1. $\phi_{S}>1$ so that condition (40) always holds and the symmetric equilibrium is unstable for any value of $\phi$.

2. $\phi_{S}<0$ so that condition (40) never holds and the symmetric equilibrium is stable for any value of $\phi$.

3. $0 \leq \phi_{S} \leq 1$ so that the stability properties of the symmetric equilibrium depend on $\phi$.

We can summarise the case when capital is mobile as follows. Allowing for the elasticity of substitution to be larger than $1\left(\frac{1}{1-\alpha} \geq 1\right)$ and assigning a zero value to the "love for variety" parameter $(v=0)$, the dynamic properties of the symmetric equilibrium change substantially with respect to the case when $\frac{1}{1-\alpha}=$ 1 and $v=\frac{1}{\sigma-1}$. In particular, when $\phi$ is low enough $\left(\phi<\phi_{S}\right)$, catastrophic agglomeration may occur even with perfect capital immobility. Even if the south maintains the ownership of their firms relocated to the north, southern consumers enjoy a lower level of steady state utility since they have to afford higher prices due to the presence of transport costs. In this case, agglomeration leads to a static loss for consumers which might or might not be compensated for by the dynamic gain due to the presence of localized spillovers.

When capital is immobile, things are much clearer: the presence of a further agglomeration force (the price effect) guarantees that the symmetric equilibrium becomes unstable for even higher values of transport costs (i.e.: lower values of $\phi)$. This seems to be enough to claim that, with $\alpha \geq 0, v=0$, and with capital immobility and $\phi$ sufficiently high, catastrophic agglomeration occurs with probability 1.

\subsection{Growth, integration and the geographical allocation of industries}

Another clear result of NEGG models is that, when knowledge spillovers are not localized, the growth rate of innovation is not influenced by the geographical allocation of firms. In other words, when the cost of innovation is the same across space, geography does not affect growth. We show that this is not the case when we allow for the elasticity of substitution to be larger than 1: in this case geography does matter for growth when spillovers are global. For simplicity's sake, we still limit the analysis to the case when $v=0$. We will focus on the case when capital is immobile and spillovers are global and calculate and compare the rate of growth of innovation in the symmetric and CP equilibrium. In the symmetric equilibrium, Tobin's $q$ is equal to 1 for both regions

$$
q=q^{*}=\frac{E^{w} \mu\left(\frac{1}{2}, \phi\right)}{\sigma(\rho+g)}=1
$$


Solving for $E^{w}$ and using (39) we finally find

$$
g_{S}=\frac{2 L \mu\left(\frac{1}{2}, \phi\right)-\rho\left(\sigma-\mu\left(\frac{1}{2}, \phi\right)\right)}{\sigma}
$$

which looks very similar to (12): the only difference is that now $\mu$, the expenditure shares for the $M-$ good, is not constant but it may differ across regions and it is a positive function of the freeness of trade by (30) and (31). This gives us

$$
\frac{\partial g_{S}}{\partial \phi}=\frac{\partial \mu}{\partial \phi} \frac{1}{\sigma}(2 L+\rho)>0
$$

and enables us to conclude that when the elasticity of substitution is larger than 1 , the rate of growth of innovation is positively influenced by the process of economic integration. Thus integration has a growth effect. Why is this so? A higher $\phi$ means a larger expenditure share for $M$ - goods in both regions. This increase leads to higher profits which means, ceteris paribus, that there is a larger incentive for manufacturing firms to invest in R\&D. We should stress that this growth-effect of integration is not present in the typical NEGG model.

As for the CP equilibrium, we make use of the condition according to which $q^{*}=0$ and $q=1$. In particular

$$
q=\frac{\pi}{(\rho+g) \sigma}=\left[s_{E} \mu(1, \phi)+\left(1-s_{E}\right) \mu^{*}(1, \phi)\right] \frac{E^{w}}{\sigma(\rho+g)}=1
$$

Since $E^{*}=L$ when $s_{K}=s_{n}=1$ we find

$$
E=\frac{\sigma(\rho+g)-L \mu^{*}(1, \phi)}{\mu(1, \phi)}
$$

Using (35) with $s_{n}=1$, we also have

$$
E=\frac{(L-g) \sigma+L \mu^{*}(1, \phi)}{\sigma-\mu(1, \phi)}
$$

by equating these two expressions we finally get

$$
g_{c p}=\frac{L\left[\mu(1, \phi)+\mu^{*}(1, \phi)\right]-\rho(\sigma-\mu(1, \phi))}{\sigma} \neq g_{S}
$$

This expression confirms that integration is good for growth $\left(\frac{\partial g_{c p}}{\partial \phi}>0\right)$ and sheds light on the fact that geography matters for growth even when spillovers are global. Indeed we can observe that

$g_{c p}>(<) g_{S}: L\left[\mu(1, \phi)+\mu^{*}(1, \phi)-2 \mu\left(\frac{1}{2}, \phi\right)\right]>(<) \rho\left(\mu\left(\frac{1}{2}, \phi\right)-\mu(1, \phi)\right)$

The right member is surely negative, being $\mu\left(\frac{1}{2}, \phi\right)<\mu(1, \phi)$. So that a sufficient (but not necessary) condition for agglomeration to be growth-enhancing 
is that the sum of the expenditures shares for the $M$-goods in the two regions is larger in the CP than in the symmetric equilibrium.

$$
\mu(1, \phi)+\mu^{*}(1, \phi)>2 \mu\left(\frac{1}{2}, \phi\right)
$$

This condition may or may not hold according to the values of the parameters $\delta, \alpha$ and $\sigma$ but, in any case, a change in the geographical allocation of industries will affect the rate of growth of innovation through its effect on the expenditure shares and hence on profits. In particular, there is surely a subset of parameter values such agglomeration is detrimental to growth in both countries.

\subsection{Full specialization and uneven growth}

In this section we will try to give an idea of why the conclusion according to which long-run real income growth rates are identical across countries is far from robust. The reason for the absence of long-run growth differentials in the typical NEGG model is to be found in the continual terms-of-trade gains. Thanks to technological progress in the industrial sector, the price index of manufactured goods decreases faster than that of the agricultural goods. This implies that the relative value of the commodity in which the periphery specializes - agricultural goods - increases overtime making the periphery's imports of manufacturing goods cheaper. This positive effect on the periphery's permanent income perfectly offsets the negative effect of slower productivity growth in the traditional sector. As already stated, this result strongly suggests policy rules that favour agglomeration of industrial activities since, in any case, the periphery would not suffer from any dynamic loss associated to the loss of the industrial sector. But is this always the case? What assumptions are needed in order to obtain this important result? And is the result robust to slight changes in this assumption?

One way to answer these questions can be found in a simple model of endogenous growth and trade contained in Lucas (1988). The economy considered by Lucas consists of two goods (a high-tech and a low-tech good, just like in NEGG models) and a continuum of trading countries. Consumers of each country choose how to allocate their income between the two goods according to a CES utility function. In a simple framework with zero transport costs, homogeneous goods and no capital accumulation (pure learning-by-doing growth), Lucas shows that: 1) countries specialize in the production of the good in which they have a (dynamic) comparative advantage; 2) long-run growth rate of real income differs across countries whenever the elasticity of substitution between high and low-tech goods is non-unitary. In particular, when the elasticity of substitution is greater than 1 (which is considered by Lucas the most interesting case) countries producing (having a comparative advantage in) high-learning goods, will experience a higher-than-average real growth.

The mechanism behind this important result relies on the fact that, when goods are good substitutes, the terms of trade effects (the ever-increasing relative value of the low-tech good that makes the high-tech good relatively cheaper 
for the low-tech countries) is dominated by the direct effect of productivity. In other words, low-tech countries experience a lower growth because the relative value of low-tech goods does not increase as fast as would be necessary to compensate for their slower relative productivity rate of growth.

What happens to long-run growth gap between countries in a typical NEGG model if we allow, as in Lucas (1988), the elasticity of substitution between traditional and manufacturing goods to be larger than 1 ? The relevance of this question appears to be very important for policymakers because, if Lucas' results can be replicated in a NEGG model, then policies that favours agglomeration may give rise to ever-increasing regional inequalities.

We shall now analyse problem posed by the introduction of such a generalization in a NEGG model and we will show that, with $\alpha>0$ and love for variety $(v>0)$, the two countries do not generally grow at the same rate in real terms. It is worth stressing that this result does not depend on full specialization per se. This is shown by Bellone and Maupertuis (2003) who, allowing for complete specialization in a typical NEGG model, and therefore for unequal wages between countries (as in Grossman-Helpman 1991), obtain that the "industrial" country may enjoy a higher level of real income with respect to the "agricultural" country but, since wages are constant in equilibrium, the two countries grow at the same rate in real terms. Being the expenditure shares are constant because of CD preferences and thanks to "love for variety" which constantly lowers the perceived index price for manufactures, the "agricultural" country is still able to enjoy a constant increase in the relative price of the good it produces which is exactly equal to the loss in the relative productivity given by the fact that only the industrial sector (and therefore the industrial country) benefits from technological progress.

\subsubsection{Real growth and love for variety}

Before analysing whether or not there is a case in which agglomeration generates ever increasing inequalities, let us investigate the relationship between real growth (the rate of growth of real income and/or consumption) and love for variety (measured by the parameter $v$ ).

We first notice that the case we have considered so far, $v=0$ and $\alpha \geq$ 0 , is associated to a situation of real growth equal to zero in both countries regardless of the geographical allocation of industries and the degree of economic integration. Let us see how this result is reached. First of all we can notice that, in equilibrium, both expenditures and nominal income are constant in both regions. As for expenditure we simply refer to (35) which tells us that world expenditure is constant in steady state since it is a function of variables $\left(s_{n}, s_{E}, L\right.$ and $g$ ) which are all constant in steady state. And since $s_{E}$ must be constant too, also $E$ and $E^{*}$ do not change along the balance growth path either. As for 
nominal income, we can note that

$$
\begin{aligned}
Y & =L+\left[\frac{s_{E}}{s_{n}+\phi\left(1-s_{n}\right)} \mu\left(s_{n}, \phi\right)+\frac{\phi\left(1-s_{E}\right)}{\phi s_{n}+\left(1-s_{n}\right)} \mu^{*}\left(s_{n}, \phi\right)\right] \frac{E^{w}}{\sigma} \\
Y^{*} & =L+\left[\frac{\phi s_{E}}{s_{n}+\phi\left(1-s_{n}\right)} \mu\left(s_{n}, \phi\right)+\frac{\left(1-s_{E}\right)}{\phi s_{n}+\left(1-s_{n}\right)} \mu^{*}\left(s_{n}, \phi\right)\right] \frac{E^{w}}{\sigma}
\end{aligned}
$$

These expressions tell us, again, that $Y$ and $Y^{*}$ are also constant in steady state.

But in order to calculate the real growth rate we need an expression for the perfect price index associated to the CES utility function (23). This is given ${ }^{14}$ for the two regions, by

$$
\begin{aligned}
& P=\left(P_{M}^{\frac{\alpha}{\alpha-1}} \delta^{\frac{1}{1-\alpha}} n^{w^{\frac{1}{1-\sigma}\left(\frac{\alpha}{1-\alpha}\right)}}+(1-\delta)^{\frac{1}{1-\alpha}}\right)^{\frac{\alpha-1}{\alpha}}
\end{aligned}
$$

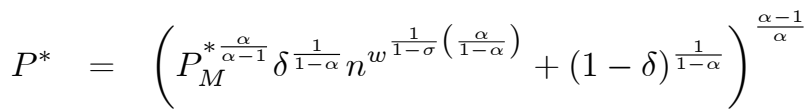

Since $\frac{\dot{P}_{M}}{P_{M}}=\frac{\dot{P}_{M}^{*}}{P_{M}^{*}}=-\frac{g}{\sigma-1}$ and $\frac{\dot{n}^{w}}{n^{w}}=g$ in steady state, we can easily conclude that, with $v=0$,

$$
\frac{\dot{P}}{P}=\frac{\dot{P}^{*}}{P^{*}}=0
$$

and, therefore,

$$
\frac{\dot{Y}}{Y}-\frac{\dot{P}}{P}=\frac{\dot{Y}^{*}}{Y^{*}}-\frac{\dot{P}^{*}}{P^{*}}=0
$$

If we maintain the assumption of $v=0$ (indifference for variety), it is worth noting that this result also holds when we use a CD second-stage utility function which is a particular case of the CES utility function we have used so far in this section $^{15}$. A certain degree of love for variety is then a necessary condition in order to have real growth. However, as we have seen before, a positive degree of love for variety $(v>0)$ associated to CES utility with $\alpha>0$ leads to a situation in which the expenditure shares for manufactures are a positive function of the world stock of capital. We shall look at the consequences and the analytical difficulties associated to this feature.

\subsubsection{Agglomeration and uneven growth.}

For the sake of simplicity, we focus on a framework in which capital is immobile (we are interested in "catastrophic" agglomeration) and spillovers are global. With CES utility and strictly positive $v$, the assumption stating that

\footnotetext{
${ }^{14}$ This expression is obtained by solving the static problem of minimizing nominal expenditures given a certain level of utility.

${ }^{15}$ With CD utility function and $v=0$, the perfect price index becomes

$$
P=P_{M}^{\mu} n^{w \frac{\mu}{1-\sigma}}
$$

so that $\dot{P}=\dot{P}^{*}=0$.
} 
a single country's labour endowment will always be insufficient to meet global demand cannot be maintained. When preferences are represented by (23) this assumption requires that

$$
L<\left(\left[1-\mu\left(s_{n}, \phi, n^{w}\right)\right] s_{E}+\left[1-\mu^{*}\left(s_{n}, \phi, n^{w}\right)\right]\left(1-s_{E}\right)\right) E^{w}\left(n^{w}, s_{n}, s_{E}\right)
$$

where

$$
E^{w}\left(s_{E}, s_{n}, n^{w}, \phi\right)=\frac{\left(2 L-L_{I}-L_{I}^{*}\right) \sigma}{s_{E}\left(\sigma-\mu\left(n^{w}, s_{n}, \phi\right)\right)+\left(1-s_{E}\right)\left(\sigma-\mu^{*}\left(n^{w}, s_{n}, \phi\right)\right)}
$$

It is not easy to say what happens to the right-hand member of (44) in the long run as $K^{w}$, and therefore even $n^{w}$, grows. Our aim is not to provide a full analysis of the transitional dynamics of the model, but we can try to present the intuition as follows. Suppose we start from a symmetric equilibrium where $w=w^{*}=1$ and $s_{n}=1 / 2$ and (44) holds. For low enough values of transport costs, this equilibrium becomes also unstable (even more so) in the CES case with $\alpha>0$, that is, any positive shock on $s_{n}$ brings about a cumulative advantage to the north, reinforcing the innovation profitability. In the meantime, $\mu$ will surely grow because both $s_{n}$ and $n^{w}$ are growing. As for $\mu^{*}$, we have a positive effect given by the growth in $n^{w}$ but also a negative effect given by the growth of $s_{n}$ which makes $M$ - goods more expensive for the south. Moreover, as is clear from (45), world expenditure increases with $n^{w}$, so that the dynamic behaviour of the global demand for traditional products becomes very complex. A necessary condition for the traditional good to be produced in only one country is that global demand for traditional good is never higher than $L$ which represents the production capacity of a single country. Since $E^{w}$ is upperbounded ${ }^{16}$, the right member of (44) will surely reach the value $L$ in a finite time. So there certainly comes a time in which, thanks to the continuously decreasing price of the $M$ - goods, the global demand for the traditional goods becomes so small that a single country's labor endowment is sufficient to completely satisfy it. Then, when $\alpha>0$ and $v>0$, the traditional good will sooner or later be produced by a single country.

But since agglomeration $\left(s_{n}=1\right)$ occurs only asimptotically, the production of the $T$ - goods will be placed in only one region before the agglomeration process has ended. The theory of comparative advantage suggest us that, at that time, the country which will produce the traditional good will be the one having a comparative advantage on it, that is, the one who is gradually losing its industrial sector and thus has a comparative disadvantage in the production of the $M$ - good (say the south). What is the effect of such an event in the ongoing agglomeration process? Since wages will rise in the north, the agglomeration

${ }^{16}$ When capital grows overtime at the constant rate $g$, we have that

$$
\lim _{t \rightarrow \infty} E^{w}\left(s_{E}, s_{n}, n^{w}, \phi\right)=\frac{(2 L-g) \sigma}{\sigma-1}
$$


process will not be reversed if and only if investment in the $\mathrm{R} \& \mathrm{D}$ and $M$ - sector remains unprofitable for the south despite its wage-cost advantage ${ }^{17}$.

It is then clear that CES preferences open the door to a number of very interesting and complex dynamics which were precluded in the CD case. At this time, we just aim at pointing out that, if an equilibrium of complete specialization exists and can be reached (i.e.: it is stable, as in Lucas (1988)), then it is charachterized by a positive real growth gap between the North and the South and therefore leads to increasing inequalities between them.

The most important consequence of full specialization is that, as in Bellone and Maupertuis (2003) when the traditional sector disappears in the North, northern wages are no longer linked to the price of the traditional good. We then have to take into account the variable $w$, that is, northern wage ${ }^{18}$. This implies, by (8), that each variety's price is now equal to $w$. Hence, when $s_{K}=s_{n}=1$, the price index for the $M$ goods becomes

$$
\begin{aligned}
& P_{M}=\left[\int_{i=0}^{K+K^{*}} p_{i}^{1-\sigma} d i\right]^{\frac{1}{1-\sigma}}=w n^{\frac{1}{1-\sigma}} \\
& P_{M}^{*}=\left[\int_{i=0}^{K+K^{*}} p_{i}^{* 1-\sigma} d i\right]^{\frac{1}{1-\sigma}}=w\left(\phi n^{w}\right)^{\frac{1}{1-\sigma}}
\end{aligned}
$$

As a consequence, even north and south expenditures shares for manufactures depend now on $w$

$$
\begin{aligned}
\mu\left(n^{w}, 1, \phi, w\right) & =\frac{1}{1+\left(n^{w}\right)^{-\frac{\alpha v}{1-\alpha}} w^{\frac{\alpha}{1-\alpha}}\left(\frac{1-\delta}{\delta}\right)^{\frac{1}{1-\alpha}}} \\
\mu^{*}\left(n^{w}, 1, \phi, w\right) & =\frac{1}{1+\left(n^{w}\right)^{-\frac{\alpha v}{1-\alpha}} w^{\frac{\alpha}{1-\alpha}} \phi^{\frac{\alpha}{(1-\alpha)(1-\sigma)}}\left(\frac{1-\delta}{\delta}\right)^{\frac{1}{1-\alpha}}}
\end{aligned}
$$

which means that their growth rate is the following

$$
\begin{aligned}
\frac{\dot{\mu}}{\mu} & =\frac{\alpha}{1-\alpha}\left(v \frac{\dot{n}^{w}}{n^{w}}-\frac{\dot{w}}{w}\right)(1-\mu) \\
\frac{\dot{\mu}^{*}}{\mu^{*}} & =\frac{\alpha}{1-\alpha}\left(v \frac{\dot{n}^{w}}{n^{w}}-\frac{\dot{w}}{w}\right)\left(1-\mu^{*}\right)
\end{aligned}
$$

Hence expenditure shares are constant if and only if $\frac{\dot{w}}{w}=v \frac{\dot{n}^{w}}{n^{w}}$. We can show that this is impossible when $\frac{\dot{n}^{w}}{n^{w}}$ is a positive constant. Let us start by taking into account three relevant market-clearing conditions.

Firstly, the world labour market has to clear all the time. In general, we must have that $2 L=\left(L_{T}+L_{T}^{*}\right)+\left(L_{M}+L_{M}^{*}\right)+\left(L_{I}+L_{I}^{*}\right)$. But, with full

\footnotetext{
${ }^{17}$ Obviously, this requirement is more easily satisfied when spillovers are localized. See Bellone and Maupertuis (2003)

${ }^{18}$ Notice that $w_{I}=w_{M}=w$ since worker are mobile across sectors within the same regions.
} 
specialization

$$
\begin{aligned}
L_{T}^{*} & =L \\
L_{T} & =L_{M}^{*}=L_{I}^{*}=0 \\
L_{I} & =\frac{\dot{n}^{w}}{n^{w}}
\end{aligned}
$$

so that

$$
L=L_{M}+\frac{\dot{n}^{w}}{n^{w}}
$$

Secondly, as the $M$ - goods market has to clear, the value of total production (which when $s_{K}=1$ corrensponds to the value of north production) must be equal to total expenditure. Since with complete agglomeration we have $E^{*}=L$, then

$$
w L_{M} \frac{\sigma}{\sigma-1}=E \mu+L \mu^{*}
$$

Finally, the traditional goods market has to clear too and therefore the value of total production (which in full specialization corresponds to the south's production) must be equal to total expenditures for the $T$ goods

$$
E(1-\mu)+L\left(1-\mu^{*}\right)=L
$$

Notice that this last condition is very similar to the no-full-specialization condition (7). Once we have introduced the new variable $w$, this condition can (and has to!) hold with equality: south production of $T$ - good must be equal to global demand for $T$ - goods. Using (52), (53) and (54) we find that

$$
E=\frac{\sigma w\left(L-\frac{\dot{n}^{w}}{n^{w}}\right)}{\sigma-1}
$$

This expression tells us that, in complete specialization, northern expenditure $E$ and northern wage rate $w$ must grow at the same rate in order to constantly clear the market.

By (54) we obtain

$$
E \frac{1-\mu}{\mu^{*}}=L
$$

so that, differentiating with respect to time, we have

$$
\frac{\dot{E}}{E}-\frac{\dot{\mu}}{1-\mu}-\frac{\dot{\mu}^{*}}{\mu^{*}}=0
$$

Substituting for (50) and (51) and since $\frac{\dot{E}}{E}=\frac{\dot{w}}{w}$, we have that

$$
\frac{\dot{w}}{w}=\frac{\alpha+\alpha\left(\mu-\mu^{*}\right)}{1+\alpha\left(\mu-\mu^{*}\right)} v \frac{\dot{n}^{w}}{n^{w}}<v \frac{\dot{n}^{w}}{n^{w}}
$$

In other words, northern wages have to grow in order to constantly maintain the market-clearing conditions but their growth is not large enough to offset 
the positive effect on prices of the growth of $n^{w}$. Hence both $\mu$ and $\mu^{*}$ increase and approach the unit value for $t \rightarrow \infty$. This is a considerable problem because it means that the balanced growth path can only be reached asimptotically. But even without formalizing the transitional dynamics, we can conclude that during this transition the two countries do not share the same real growth rate. First, we know that prices will decrease faster in the north. Indeed, we have

$$
\begin{aligned}
\dot{P} & =\frac{w^{\frac{\alpha}{\alpha-1}} \delta^{\frac{1}{1-\alpha}} n^{\frac{v \alpha}{1-\alpha}}}{w^{\frac{\alpha}{\alpha-1}} \delta^{\frac{1}{1-\alpha}} n^{w^{\frac{v \alpha}{1-\alpha}}}+(1-\delta)^{\frac{1}{1-\alpha}}}\left(\frac{\dot{w}}{w}-v \frac{\dot{n}^{w}}{n^{w}}\right) \\
\dot{P}^{*} & =\frac{w^{\frac{\alpha}{\alpha-1}} \phi^{\frac{1}{1-\sigma}} \frac{\alpha}{\alpha-1} \delta^{\frac{1}{1-\alpha}} n^{w^{\frac{v \alpha}{1-\alpha}}}}{w^{\frac{\alpha}{\alpha-1}} \phi^{\frac{1}{1-\sigma} \frac{\alpha}{\alpha-1}} \delta^{\frac{1}{1-\alpha}} n^{w^{\frac{v \alpha}{1-\alpha}}}+(1-\delta)^{\frac{1}{1-\alpha}}}\left(\frac{\dot{w}}{w}-v \frac{\dot{n}^{w}}{n^{w}}\right)
\end{aligned}
$$

so that $\frac{\dot{P}}{P}<\frac{\dot{P}^{*}}{P^{*}}$. Second, we know that southern expenditure remains fixed at level $L$, which corrensponds to the value of production of the traditional good. Third, since both $\mu$ and $\mu^{*}$ increase over-time, by (56) we also see that northern expenditure $E$ increases. We can therefore conclude that

$$
\frac{\dot{E}}{E}-\frac{\dot{P}}{P}>\frac{\dot{E}^{*}}{E^{*}}-\frac{\dot{P}^{*}}{P^{*}}=-\frac{\dot{P}^{*}}{P^{*}}
$$

so that, unlike in the $\mathrm{CD}$ case, real consumption growth is higher in the core than in the periphery. In a similar way, we can show that there is a positive gap between north and south real income growth.

Summing up, we have argued that the result indicating that real growth rates will be the same in both countries regardless of the geographical allocation of industries is a very particular case and it's not robust to slight changes in the assumption of the model. In particular, when the elasticity of substitution between the two kinds of goods may assume any value between 1 and $\infty$, it might well be that the core grow faster than the periphery in real terms. This result seems to have important consequences for policymakers since, in this case, policies that favour agglomeration may generate ever-increasing regional inequalities. This more pessimistic viewpoint on the effects of agglomeration on core-periphery patterns is indirectly supported by the empirical evidence showing that the expenditure share in the agricultural good is decreasing as real income increases - a phenomenon compatible with an elasticity of substitution greater than one.

\section{Conclusion}

In this chapter we have dealt with the issue of the relationship between the agglomeration of economic activities and economic growth. In the first part we have surveyed the main results of a typical "New Economic Geography and Growth" (NEGG) model and we have seen how these results might be helplful in drawing up regional policy rules which favour the concentration of activities in only one region. In the second part of the paper we challenged this optimistic 
vision of the consequences of agglomeration and we showed how these results are crucially based on very restrictive values of some parameters of the model and how they are sensitive to slight changes in these values. In particular we have provided some analytical examples in which, according to different values of the degree of love for variety and of the elasticity of substitution between traditional and manufacturing goods, it is evident that a) when trade is costly enough the symmetric equilibrium might not be stable even when capital is perfectly mobile; b) the rate of growth might depend on the geographical allocation of industries even when spillovers are global; and, c) when industrial firms are concentrated in only one region, countries might not grow at the same rate in real terms. The main message of our analysis is that policymakers should be aware of the fact that implementing regional policy rules suggested by NEGG models might actually harm the periphery. In other words, the effect of agglomeration might be more dangerous than what commonly thought so far. This message is all the more relevant if we consider that we have only focused on some particular aspects of NEGG models while there are other issues which deserves closer scrutiny. For example, what happens if we allow for intersectoral spillovers between the traditional and the manufacturing sector? This appears to be an important shortfall of NEGG models since our common sense suggest that knowledge might flows across sectors too. If we introduce some kind of intersectoral spillovers by allowing for technological progress even in the traditional sector, which benefits from the proximity of the domestic $\mathrm{R} \& \mathrm{D}$ or/and the manufacturing sector only, then agglomeration might be even more dangerous for the periphery since it would remove an important engine of growth. This result would be compatible with some empirical evidence according to which the traditional sector is more productive in "industrial" countries. On the other hand, whenever we allow for technology to flow across regions with different specializations (in accordance with the evidence reported by Di Liberto, Mura and Pigliaru (2004)), then the negative growth impact of agglomeration discussed in Section 3.4 might well be mitigated. An intuition for that is provided by Murat and Pigliaru (1998) which generalize Lucas (1988) by introducing intersectoral and international spillovers: in such an analytical context, uneven growth is always ruled out and the only kind of damage for the periphery (i.e. the "agricultural" country) is a static one. But detailed analysis of the impact of intersectoral spillovers in NEGG models (which appears to be strongly needed) is left for future research.

\section{References}

[1] Baldwin, R. (1999), "Agglomeration and Endogenous Capital", European Economic Review 43, 253-280

[2] Baldwin, R. and R. Forslid (1999), "Incremental Trade Policy and Endogenous Growth: a q-theory approach", Journal of Economic Dynamics and Control 23, 797-822. 
[3] Baldwin, R. and R. Forslid (2000a), "The Core-Periphery Model and Endogenous Growth: Stabilizing and De-Stabilizing Integration" Economica 67, 307-324.

[4] Baldwin, R. and R. Forslid (2000b), "Trade Liberalisation and Endogenous Growth, a q-theory approach", Journal of International Economics 50, 497517.

[5] Baldwin, R. and P. Martin (2003), "Agglomeration and Regional Growth", CEPR discussion paper n. 3960.

[6] Baldwin, R. P. Martin and G.M. Ottaviano (2001), "Global Income Divergence, Trade and Industrialization: The Geography of Growth Take-offs", Journal of Economic Growth 6, 5-37

[7] Baldwin, R., R. Forslid, P. Martin, G. Ottaviano and Robert-Nicoud (2003), Economic Geography and Public Policy, Princeton University Press.

[8] Bellone F. and M.A. Maupertuis (2003), "Economic Integration and Regional Income Inequalities: Competing Dynamics of Regional Wages and Innovative Capabilities", Review of International Economics, 11, 512-526.

[9] Benassy J.P. (1996), "Taste for variety and optimum production patterns in monopolistic competition", Economic Letters, 52, 41-47.

[10] Blanchard O.J. and N.Kiyotaky, "Monopolistic Competition and Aggregate Demand", American Economic Review, 77, 647-666.

[11] Di Liberto A, Mura R. and F. Pigliaru (2004), "How to measure the unobservable: a panel tecnique for the analysis of TFP convergence", CRENoS Working Paper 04/05.

[12] Dixit A.K. and J.E. Stiglitz (1975), "Monopolistic Competition and optimum product diversity", Economic Research Paper No. 64, University of Warwick.

[13] Dixit A.K. and J.E. Stiglitz (1977), "Monopolistic Competition and optimum product diversity", American Economic Review 67, 297-308.

[14] Grossman, G. and E. Helpman (1991), Innovation and Growth in the World Economy, Cambridge MA: MIT Press.

[15] Fujita M. and J.F. Thisse (2002), Economics of Agglomeration: Cities, Industrial Location and Regional Growth, Cambridge: Cambridge University Press.

[16] Lucas, R.E. (1988) "On the Mechanics of Economic Development", Journal of Monetary Economics 22, 3-42.

[17] Krugman, P. (1991), "Increasing Return and Economic Geography", Journal of Political Economy 99, 483-99. 
[18] Krugman, P. R. and A. J. Venables (1995), "Globalization and the Inequality of Nations", Quarterly Journal of Economics 60, 857-880.

[19] Kaldor N. (1970) "The Case for Regional Policies", Scottish Journal of Political Economy 80, 337-348.

[20] Martin P. (1999), "Public Policies, Regional Inequalities and Growth", Journal of Public Economics 73, 85-105

[21] Martin, P. and G. Ottaviano (1999), "Growing Locations: Industry Location in a Model of Endogenous Growth", European Economic Review 43, 281-302.

[22] Martin, P. and G. Ottaviano (2001), "Growth and Agglomeration", International Economic Review 42, 947-968

[23] Murat M. and F. Pigliaru (1998), "International Trade and Uneven Growth: A Model With Intersector Spillovers of Knowledge", Journal of International Trade and Economic Development, 7, 221-236.

[24] Murata Y. (2004) "Structural Change and Agglomeration", paper presented at the CEPR workshop on Economic Geography, Paris 16-18 june, 2004 .

[25] Moreno R, R. Paci and S. Usai (2003), "Spatial spillovers and innovation activity in European regions" CRENoS Working Paper 03/10, forthcoming in Environment and Planning.

[26] Romer P., (1990). "Endogenous Technological Change", Journal of Political Economy 98.5, S71-S102.

[27] Smulders S. and T. Van de Klundert, "Monopolistic Competition and Economic Growth" in Brakman S. and B.J. Heijdra, Eds., The Monopolistic Competition Revolution in Retrospect, Cambridge: Cambridge University Press.

[28] Yamamoto K. (2002), "Agglomeration and growth with innovation in the intermediate goods sector", Regional Science and Urban Economics 33, 335-360. 